\title{
Glycosylation of the flagellin of the polar flagellum of Azospirillum brasilense, a Gram-negative nitrogen-fixing bacterium
}

\author{
Sara Moens, ${ }^{1}$ Kris Michiels ${ }^{2}$ and Jos Vanderleyden ${ }^{1}$ \\ Author for correspondence: Jos Vanderleyden. Tel: +32163224 03. Fax: +3216322990. \\ e-mail: Janssens@agr.kuleuven.ac.be
}

\author{
1 F. A. Janssens Laboratory \\ of Genetics, Catholic \\ University of Leuven, \\ Willem de Croylaan 42, \\ B-3001 Heverlee, Belgium \\ 2 Laboratory of Food \\ Microbiology, Catholic \\ University of Leuven, \\ Kardinaal Mercierlaan 92, \\ B-3001 Heverlee, Belgium
}

\begin{abstract}
The glycosylation of the flagellin of the polar flagellum of Azospirillum brasilense Sp7 is demonstrated in several ways: (1) by a decrease in apparent $M_{r}$ after chemical deglycosylation; (2) by sugar staining after SDS-PAGE; (3) by use of a sugar-specific monoclonal antibody in immunogold labelling coupled with transmission electron microscopy. In addition, two mutant flagellins are described; they differ in glycan composition when compared with the wildtype. The glycosylation of a bacterial flagellin is unusual and has to be taken into account in the proposed model for the assembly of the flagellar filament.
\end{abstract}

Keywords: Azospirillum brasilense, glycosylation, bacterial glycoprotein, polar flagellin, glycosylation mutants

\section{INTRODUCTION}

Azospirilla are plant-root-associated nitrogen-fixing bacteria able to promote plant growth (Okon, 1994). In view of their possible application as a biofertilizer, the molecular mechanisms that govern the association of these bacteria with plant roots are of interest.

An Azospirillum brasilense cell can display two types of flagella: one polar flagellum that is present under all growth conditions and, in addition, several lateral flagella that are only synthesized on (semi-)solid surfaces (Tarrand et al., 1978). The polar flagellum is responsible for the locomotion in liquid medium (swimming), while the lateral flagella are believed to be involved in swarming over solid surfaces (Hall \& Krieg, 1983). It has been suggested that, in natural environments, free swimming through the water space, rather than swarming, is needed for migration to plant roots because of the dependence of this migration on soil moisture (Bashan, 1986; Zhulin \& Armitage, 1993).

Previous work in our laboratory revealed the presence of several loci involved in motility on the chromosome and the $90 \mathrm{MDa}$ plasmid (p90) of $A$. brasilense Sp7 (van Rhijn et al., 1990; Croes et al., 1991). Croes et al. (1991) replaced large parts of the $\mathrm{p} 90$ plasmid DNA with a kanamycinresistance-encoding gene cassette. In mutant $\Delta 071$, approximately $14 \mathrm{~kb}$ is deleted and this resulted in an

Abbreviations: mAb2, class 2 monoclonal antibody; p90, 90 MDa plasmid of $A$. brasilense; PAVS staining, periodic acid/Schiff staining; TEM, transmission electron microscopy; TFMS, trifluoromethanesulfonic acid. altered motility. Replacing another part of p 90 (mutant $\Delta 084)$ resulted in a non-flagellate phenotype and a reduced capacity to adsorb to plant roots. This result, together with several additional lines of evidence, demonstrated unequivocally that the polar flagellum promotes adsorption of $A$. brasilense to plant roots (Croes et al., 1993). Bacterial adsorption is believed to be a key step in plant root colonization, which in turn is essential for plant growth promotion.

Glycosylation of proteins in prokaryotes is a rather recent research topic but seems to be widespread in both the domain of the Archaea and the domain of the Bacteria (Woese et al., 1990). The first chemically characterized example is the cell surface protein of the archaeobacterium Halobacterium balobium (Mescher \& Strominger, 1976; Wieland et al., 1982). More recently, evidence has also been provided for the occurrence of glycoproteins in Bacteria, most of them Gram-positive. The best studied examples of bacterial glycoproteins are surface layer (Slayer) proteins (Messner \& Sleytr, 1991, 1992). Non-Slayer glycoproteins have been reported but only in a few cases have structural studies been performed (for a review, see Sandercock et al., 1994).

Glycosylation of flagellin has to our knowledge only been reported for some Archaea (Lechner \& Wieland, 1989; Wieland et al., 1985; Southam et al., 1990; Kalmokoff et al., 1992; Yao et al., 1992) and is possibly also present in minor flagellar polypeptides of Spirochaeta aurantia (Brahamsha \& Greenberg, 1988). Several other posttranslational modifications of flagellin such as phosphorylation (Kelly-Wintenberg et al., 1993; Logan et 
al., 1989), methylation (Ambler \& Rees, 1959) and sulfatation (Wieland et al., 1985) have been reported.

Here we provide evidence that the flagellin of the polar flagellum of the Gram-negative bacterium $A$. brasilense $\mathrm{Sp} 7$ is a glycoprotein. This flagellin is designated Fla1 to discriminate it from the flagellin, Laf1, of the lateral flagella. We also describe glycosylated flagellins of two previously described p 90 mutants that are affected in their glycan moiety when compared with the wild-type. Mutant $\Delta 071$ is one of the p90 deletion mutants (Croes et al., 1991 ); the exoC mutant has a $\operatorname{Tn} 5$ transposon insertion in a gene encoding a phosphomannomutase (Michiels et al., 1988; Petersen \& Vanderleyden, 1994). To our knowledge, such glycosylation mutants have never been reported.

\section{METHODS}

Bacterial strains and growth conditions. The Azospirillum brasilense strains used are listed in Table 1. Cells were grown at $30^{\circ} \mathrm{C}$ on Luria-Bertani medium (Sambrook et al., 1989), supplemented with $2.5 \mathrm{mM} \mathrm{CaCl}_{2}$ and $2.5 \mathrm{mM} \mathrm{MgSO}_{4}$. For the mutant strains, kanamycin was added at a concentration of $25 \mu \mathrm{g} \mathrm{ml} \mathrm{l}^{-1}$.

Isolation of $\boldsymbol{A}$. brasilense polar and lateral flagella. This procedure was as described by Schloter et al. (1994). Briefly, cells grown on agar plates were collected in a small volume of a Tris buffer. Flagella were sheared in a blender and the cell bodies were separated from the flagella using differential centrifugation. The two types of flagella were separated using a $\mathrm{CsCl}$ density gradient.

Chemical deglycosylation of flagellin. Sugar residues were removed from the flagellins using the GlycoFree Chemical Deglycosylation kit of Oxford Glycosystems.

One-dimensional gel electrophoresis (SDSPAGE) and Western blotting. The discontinuous SDS gel system described by Laemmli (1970) was used with a $5 \%(\mathrm{w} / \mathrm{v})$ stacking gel and a $12 \%(\mathrm{w} / \mathrm{v})$ resolving gel. The samples were boiled for $5 \mathrm{~min}$ in sample buffer. The resulting gels were stained with Coomassie brilliant blue R250 or electroblotted onto an Immobilon-P membrane (Millipore).

Sugar staining of blotted proteins. Periodic acid/Schiff (PA/S) staining was done according to the method of Strömqvist \& Grufmann (1992). Vicinal diols in the sugar residues of blotted proteins were oxidized with periodic acid and subsequently treated with Schiff's reagent. The Glycan Detection kit was purchased from Boehringer Mannheim. This kit also uses periodic acid oxidation of blotted proteins. Subsequently a digoxigenin group is coupled to the aldehydes formed. The digoxigenin is then detected using an alkalinephosphatase-coupled anti-digoxigenin antiserum. The latter method proved in this case to be more sensitive than the detection with Schiff's reagent.

Immunodetection of non-treated and periodic-acid-oxidized flagellin. We adopted the procedure of Woodward et al. (1985) with some modifications. All incubations were done at room temperature. The blots were blocked for $30 \mathrm{~min}$ in $0.1 \%$ BSA/PBS $\left(\mathrm{g} \mathrm{l}^{-1}: \mathrm{NaCl}, 8 \cdot 0 ; \mathrm{KCl}, 0 \cdot 2 ; \mathrm{Na}_{2} \mathrm{HPO}_{4}, 1 \cdot 44 ; \mathrm{KH}_{2} \mathrm{PO}_{4}\right.$, $0.24 ; \mathrm{pH} \mathrm{7.2)}$ and subsequently rinsed with a $50 \mathrm{mM}$ sodium acetate buffer ( $\mathrm{pH} 4 \cdot 5)$. Oxidation of the blots took place during a $1 \mathrm{~h}$ incubation in the dark in a freshly made solution of $10 \mathrm{mM}$ periodic acid in the sodium acetate buffer. In the meantime, the blots for immunodetection of non-oxidized flagellin were incubated in buffer without periodic acid. After a rinse in sodium acetate buffer, aldehyde groups were reduced with a fresh solution of $50 \mathrm{mM}$ sodium borohydride in PBS for $30 \mathrm{~min}$. At this stage, the blots are ready for immunodetection. This was done according to the method of Harlow \& Lane (1988). The blots were rinsed twice in $0.1 \% \mathrm{BSA} / \mathrm{PBS}$, incubated for $1 \mathrm{~h}$ with the class 2 monoclonal antibody mAb2 (Schloter et al., 1994), washed once with PBS and twice with TBS $\left(\mathrm{g}^{-1}: \mathrm{NaCl}\right.$, $8.0 ; \mathrm{KCl}, 0.2$; Tris, $3.0 ; \mathrm{pH} \mathrm{8.0)}$, incubated for $1 \mathrm{~h}$ with secondary antibody [goat anti-rabbit IgG $(\mathrm{H}+\mathrm{L})$ alkaline phosphatase conjugate, Bio-Rad] diluted $1: 3000$ in $0 \cdot 1 \%$ BSA/TBS, washed again with TBS and incubated with the bromochloroindolyl phosphate/nitro blue tetrazolium substrate, which forms a black-purple precipitate at the site of enzyme binding.

Immunogold labelling of whole cells and transmission electron microscopy (TEM). Cells were taken from plates, resuspended in $0.85 \% \mathrm{NaCl}$ and treated further essentially as described by Levanony \& Bashan (1989). Briefly, cells were fixed on Formvar- and carbon-coated grids with $2 \%(v / v)$ glutaraldehyde in a $0.1 \mathrm{M}$ cacodylate buffer. After rinsing the grids with double-distilled water, non-specific binding was blocked with $1 \%(\mathrm{w} / \mathrm{v}) \mathrm{BSA}$ in PBS. The grids were transferred to the monoclonal antibody solution and incubated for $90 \mathrm{~min}$. After rinsing, blocking was repeated. The grids were incubated in the gold-labelled secondary antibody [anti-mouse IgG (whole molecule) gold conjugate $5 \mathrm{~nm}$, Sigma ImmunoChemicals] diluted 1:10 in TBS. After rinsing in TBS and rinsing with double-distilled water, the grids were examined by TEM (Philips EM 400).

\section{RESULTS}

\section{Characterization of the flagellation of wild-type Sp7 and mutants $\Delta 071$, exoC and $\triangle 084$ by SDSPAGE patterns}

Isolation of flagella and separation of polar and lateral flagella of $A$. brasilense are described elsewhere (Schloter $e t$ al., 1994). Wild-type polar flagellin, Fla1, is a protein with an apparent $M_{\mathrm{r}}$ of approximately 100000 . Repeatedly we observed at least a double band on SDS-PAGE, indicating

Table 1. A. brasilense strains used in this study

\begin{tabular}{|lll|}
\hline Strain & \multicolumn{1}{c|}{ Properties } & \multicolumn{1}{c|}{ Reference } \\
\hline Sp7 & Wild-type, ATCC 29145 & Tarrand et al. $(1978)$ \\
Sp7 exoC & Tn5-insertion mutant of Sp7 & Michiels et al. (1988) \\
Sp7 p90D071 or $\Delta 071$ & Deletion mutant of Sp7 & Croes et al. (1991) \\
Sp7 p90D084 or $\Delta 084$ & Deletion mutant of Sp7 & Croes et al. (1991, 1993) \\
\hline
\end{tabular}


(a)

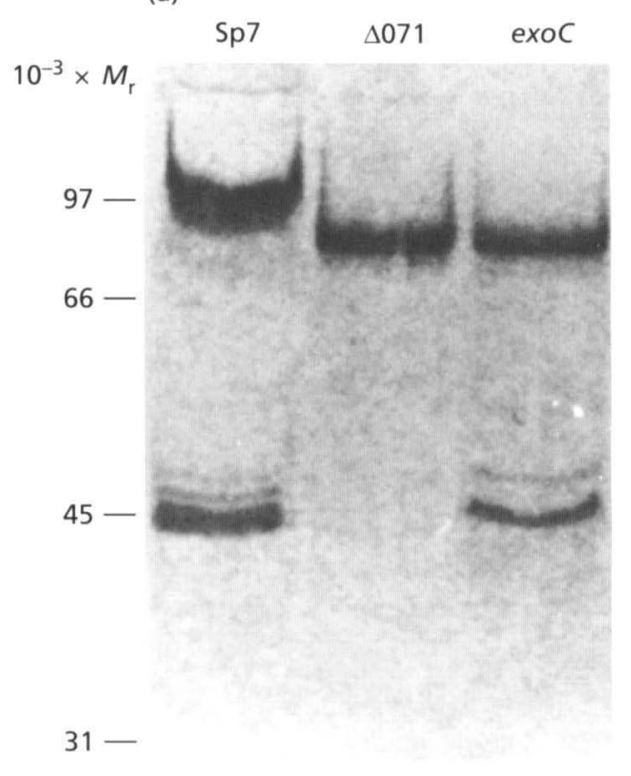

(b)

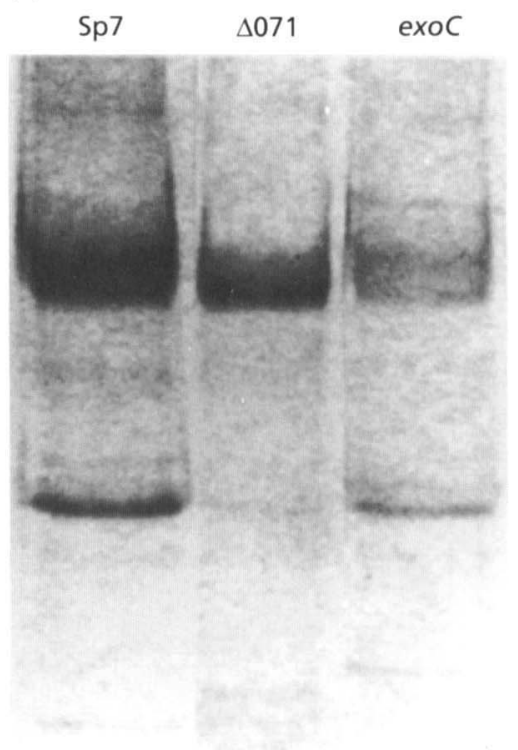

Fig. 1. (a) One-dimensional SDS-PAGE patterns (Coomassie blue staining) of the flagellins of $A$. brasilense strains Sp7, $\triangle 071$ and exoC. After TFMS deglycosylation a clear decrease in apparent $M_{r}$ of the polar flagellins is visible (b) resulting in an apparent $M_{r}$ of 70000 for the three strains. The broad band of the TFMS-treated flagellins is probably due to incomplete deglycosylation. The migration distances of the $M_{r}$ markers are indicated on the left. The identity of the contaminating protein bands with an apparent $M_{r}$ around 45000 is not known. Some of these might represent contaminating lateral flagellin. It has been noticed that they do not change in size after deglycosylation.

that there might be multiple flagellins differing in size of the protein core or the extent of post-translational modifications.

One-dimensional SDS-PAGE patterns of flagellar preparations for wild-type Sp7 and two different $\mathrm{p} 90$ mutants are compared in Fig. 1(a).

The polar flagellin of the $\mathrm{Tn} 5$-induced exoC mutant has an apparent $M_{\mathrm{r}}$ of 87000 instead of 100000 . It also has a less acidic pI than Sp7 flagellin (De Mot \& Vanderleyden, 1989). A two-dimensional PAGE preparation of exoC proteins is shown by De Mot \& Vanderleyden (1989). They designated the polar flagellin spot as a truncated protein.

Deletion mutant $\Delta 071$ has a polar flagellin with approximately the same apparent $M_{\mathrm{r}}$ as the polar flagellin of exoC. This flagellin also has a less acidic pI than wildtype Fla1 (data based on two-dimensional PAGE, not shown).

As already shown by Croes $e$ t al. (1993), the p90 deletion mutant $\Delta 084$ is non-flagellated. Consequently a 'flagellar preparation' of this bacterium does not show the Fla1 protein on SDS-PAGE gels (data not shown).

\section{Chemical deglycosylation of the Fla1 protein of strains Sp7, $\triangle 071$ and exoC}

The Glycofree Chemical Deglycosylation kit was used to attempt to remove glycosyl residues on the polar flagellins. The kit uses treatment with anhydrous trifluoromethanesulfonic acid (TFMS) and removes both $\mathrm{N}$ - and $\mathrm{O}$-glycosylation. The conditions used have been proven to cause no significant cleavage of peptide bonds. An SDS-PAGE gel of non-treated and TFMS-treated flagellins of both wild-type and mutants is shown in Fig. $1(\mathrm{a}, \mathrm{b})$. This shows clearly the decrease in apparent $M_{\mathrm{r}}$ after TFMS treatment. The apparent $M_{\mathrm{r}}$ of the TFMStreated flagellins of all tested samples is the same, approximately 70000 .

Sugar staining (PA/S) of deglycosylated flagellins was negative (data not shown) indicating the absence of carbohydrate modification, at least within the detection limits of the test system. Interestingly, the polar flagellins that are normally water soluble start to precipitate after the TFMS treatment. A possible explanation is that the sugars are responsible for a hydrophilic surface of the flagellin so that it remains in solution when the sugars are present.

\section{Sugar detection after SDSPAGE and electroblotting of 'flagellar preparations' of Sp7, $\Delta 071$, exoC and $\Delta 084$ on a polyvinylidene difluoride membrane}

Two methods for sugar detection were used, both based on periodate oxidation of the vicinal diols with subsequent detection of the aldehydes formed: PA/S staining (Strömqvist \& Grufmann, 1992) and the more sensitive Glycan Detection kit. Both methods gave a good signal for $\mathrm{Sp} 7$ polar flagellin and a slightly less intense signal for $\Delta 071$ and exoC polar flagellin. No signal was found at the same position for 'flagellar preparations' of $\Delta 084$, the 


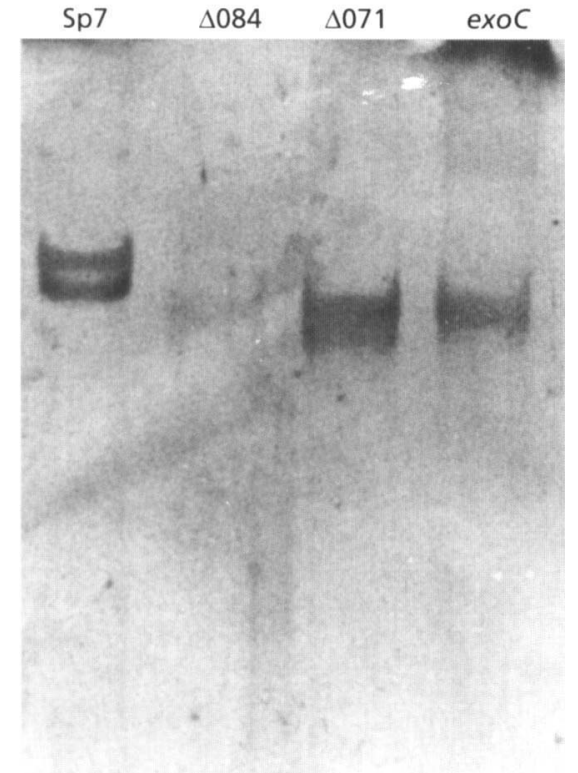

Fig. 2. Sugar detection on blotted flagellins using the Glycan Detection kit. Sp7 polar flagellin gives a clear reaction. The reaction of $\Delta 071$ and exoC polar flagellins is also clear, but is slightly less intense. No reaction is detected for $\Delta 084$. The double band, clearly visible for $\mathrm{Sp} 7$ flagellin, is discussed in the first section of Results.

flagella-less mutant (Fig. 2). This indicates that the carbohydrates are associated with the flagellins and are not just comigrating (lipo)polysaccharides. Moreover, one could expect that (lipo)polysaccharides would comigrate with other proteins as well, like the contaminating proteins with apparent $M_{\mathrm{r}}$ around 45000 that are most likely outer-membrane proteins. This is clearly not the case. On two-dimensional PAGE gels of a total protein extract of $A$. brasilense $\mathrm{Sp} 7$, sugar-specific staining was only observed for the Fla1 spot (data not shown).

Since this association of sugars with Fla1 resists boiling in $2 \%(\mathrm{w} / \mathrm{v}$ ) SDS (sample buffer), and also boiling in $10 \mathrm{mM}$ EDTA and $8 \mathrm{M}$ urea (data not shown), we conclude that the sugars are tightly associated and most likely covalently bound.

\section{Flagellin-associated carbohydrates differ from other cell surface polysaccharides}

Schloter et al. (1994) describe a set of monoclonal antibodies specifically recognizing cell surface components of $A$. brasilense $\mathrm{Sp} 7 . \mathrm{mAb} 2$ recognizes the polar flagellin of $A$. brasilense Sp7 (Fig. 3). After periodic acid treatment of blotted flagellin, no binding of $\mathrm{mAb} 2$ to flagellin is detected (data not shown), indicating that the $\mathrm{mAb} 2$ recognizes carbohydrate epitopes (Woodward et al., 1985).

Immunogold labelling coupled with TEM shows clearly the specificity of $\mathrm{mAb} 2$ for polar flagella. No colloidal

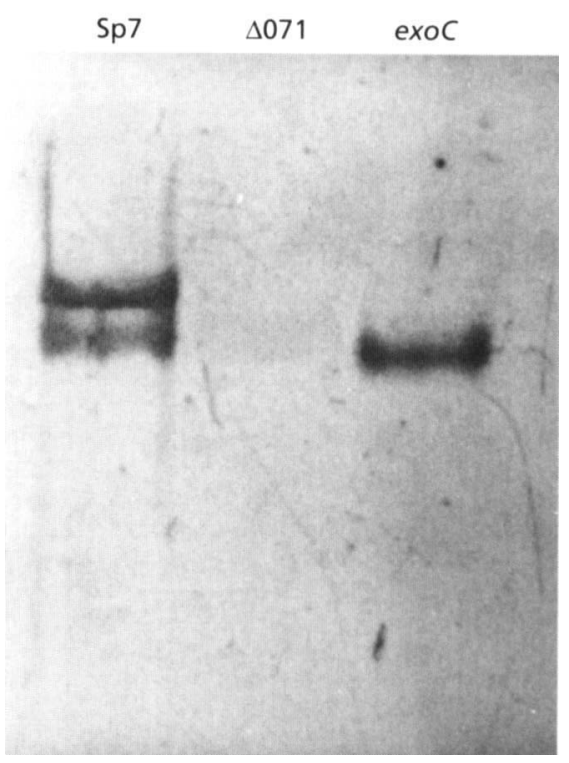

Fig. 3. Immunodetection, using mAb2, of polar flagellin blotted on a membrane, before periodic acid treatment. For Sp7, again, a clear double band is visible. This band disappears after periodate oxidation (data not shown). $\Delta 071$ polar flagellin is not recognized by $\mathrm{mAb2}$. exoC polar flagellin is also recognized only when it is not oxidized with periodate.

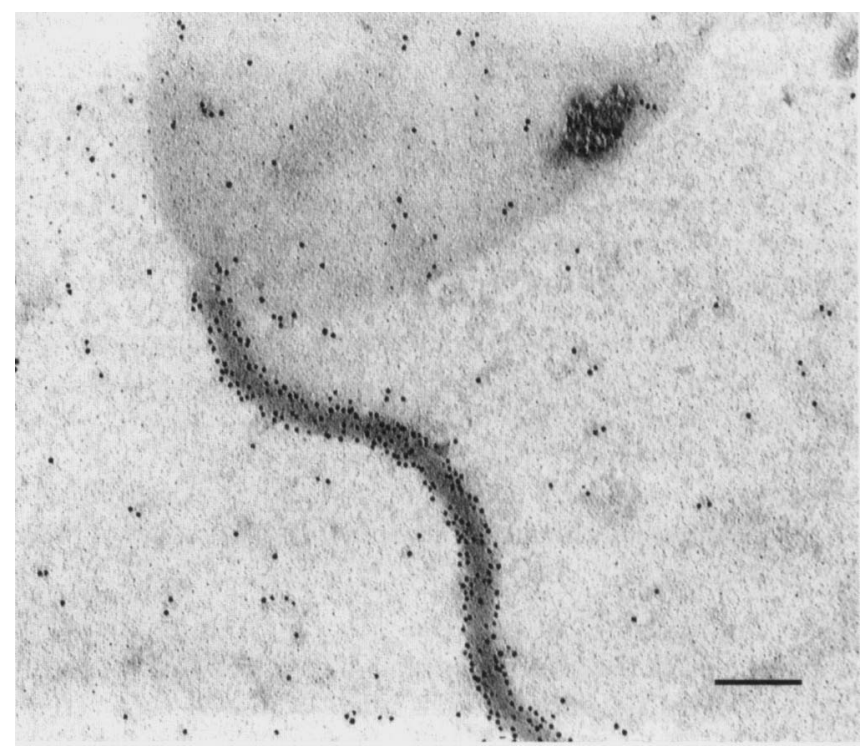

Fig. 4. Immunogold labelling using mAb2 of the polar flagellum of $A$. brasilense Sp7 observed by TEM. A clear specificity for the polar flagellum is visible. Gold particles are distributed evenly over cell surface and background. Bar, $0.1 \mu \mathrm{m}$.

gold particles are observed on lateral flagella (not shown) or on the cell surface (Fig. 4). It can be concluded that the carbohydrate epitope of $\mathrm{mAb} 2$ is specific for $\mathrm{Fla} 1$ and is not derived from a cell surface polysaccharide contamination. 
Interestingly, $\mathrm{mAb} 2$ recognizes the $e \times 0 C$ flagellin, but not the $\Delta 071$ flagellin, suggesting a difference in glycan composition between the two mutant flagellins (Fig. 3).

\section{DISCUSSION}

In this paper we provide evidence for the glycoprotein nature of the polar flagellin of $A$. brasilense Sp7.

The reported apparent $M_{\mathrm{r}}$ for the polar flagellin (100000) is unusually high since the reported apparent $M_{\mathrm{r}}$ of flagellins mainly varies between 30000 and 70000 . However, the estimated $M_{\mathrm{r}}$ is based on electrophoretic mobility in SDS-PAGE gels and does not necessarily represent the exact size of the polypeptide chain. The protein devoid of sugars, as a result of TFMS treatment, has an apparent $M_{\mathrm{r}}$ of 70000 and this corresponds more closely to the reported $M_{\mathrm{r}}$ of other flagellins.

For strains Sp7, exoC and $\Delta 071$, chemical deglycosylation of the polar flagellum preparation results in a protein with an apparent $M_{\mathrm{r}}$ of 70000 , suggesting that the protein core of the three flagellins is of the same size. Since the exoC locus has been shown recently to encode a phosphomannomutase (Petersen \& Vanderleyden, 1994) the possibility that the $\operatorname{Tn} 5$ has inserted in the structural gene for Fla1 can be excluded. A plausible explanation for the smaller size of the Fla1 in the exoC mutant is the absence of a post-translational modification on Fla1, resulting in the less acidic Fla1 protein of the exoC mutant. The data could also indicate that the deletion in $\Delta 071$ did not truncate the $f l a 1$ structural gene but that the glycosylation is affected. Moreover, it can be expected that the $\mathrm{p} 90$ DNA flanking the deletion is not encoding a part of Fla1 since, at one side, the deletion ends in the previously sequenced nodPQ genes (Vieille \& Elmerich, 1990) and, at the other side, the DNA sequence, which has also been determined previously, did not reveal an open reading frame nor any similarity to known genes (S. Moens, unpublished; Milcamps, 1993).

Glycosylation of a bacterial flagellin has not previously been reported and raises some intriguing questions about mechanisms of glycosylation and export of the flagellin molecules. Since the glycosylation process was always reported to be membrane located [in eukaryotes, and also apparently in prokaryotes (Hartmann \& König, 1989; Lechner \& Wieland, 1989; Hartmann et al., 1993), although this is not yet fully proved], the polar flagellin of $A$. brasilense would be expected to cross a membrane before entering the flagellar structure. It is believed that assembly of the extracellular structures of bacterial flagella (filament and hook) involves transport of the component proteins (flagellin and hook protein, respectively) through a central channel in the flagellar basal structure, without crossing the bacterial cell membrane in a signal-peptidedependent way. An as yet unidentified 'export apparatus' is believed to be located at the flagellar base and to be able to distinguish between the flagellar proteins to be exported and other proteins (Wilson \& Beveridge, 1993). Furthermore, it might be expected that there is a kind of barrier in the flagellar basal body in order to maintain the proton gradient across the cell membrane. This barrier might be the site where the export apparatus and the glycosylation machinery reside. Given the absence of glycosylation on the lateral flagellin (S. Moens, unpublished), the glycosylation mechanism must be localized only at the base of the polar flagellum.

In Archaea, flagellins are also glycosylated, but in this case it is assumed that the transport of flagellin resembles the leader peptide cleavage dependent transport of the type IV pilin-transport superfamily, rather than that of bacterial flagellins (Faguy et al., 1994). The presence of a leader peptide was proven for Methanococcus voltae flagellins (Kalmokoff \& Jarell, 1991). Alignment of N-terminal sequences of the other methanogen flagellins indicates that it is likely that they are also synthesized with a leader peptide (Kalmokoff et al., 1992).

It was also shown that the $S$. aurantia flagellar filament surface proteins, FlaA, which have no sequence similarity with other bacterial flagellins, have a signal peptide (Brahamsha \& Greenberg, 1989). To our knowledge, it is not yet known whether the different flagellins (FlaB) of this organism have signal peptides. However, for another spirochaete, Treponema pallidum, the FlaB proteins lack export-related signal peptides, while the FlaA proteins also have a typical export signal peptide (Penn \& Luke, 1992).

Not much is known yet about the functional tole of the glycosylation of Fla1, as is the case for the other known non-S-layer glycoproteins (Sandercock et al., 1994). Suggestions have been made about the function of the glycosylation on the flagellins of $H$. balobium and $S$. aurantia in the swimming behaviour of these organisms. For most of the peritrichously flagellated bacteria like Escherichia coli, counterclockwise (CCW) rotation of the flagella results in a left-handed helical bundle forming of the flagella, and the cell moves forward. Clockwise (CW) rotation disturbs the three-dimensional structure of the flagella, the bundle disassembles, and the cell 'tumbles' and stays at the same site. Halobacterial flagella display other properties: when the right-handed flagellar bundle turns $\mathrm{CW}$, it propels the cell forward, while a $\mathrm{CCW}$ turning bundle pulls the cell (Alam \& Oesterhelt, 1984). The glycosylation of the flagellin components could make the different flagella slide more smoothly to one another (Alam \& Oesterhelt, 1984) so that the bundle is not disassembling when the turning of the flagella changes direction. Similarly, in $S$. aurantia the glycosylation could make the flagella (located in the periplasmic space) slide more smoothly against the membranes defining the periplasmic space (Southam et al., 1990). However, glycosylation was only reported for flagellar core polypeptides. In liquid medium $A$. brasilense, however, seems to have a normal swimming behaviour for a monotrichously flagellated bacterium: CCW rotation of the filament pushes the cell forward while $\mathrm{CW}$ rotation causes a reorientation of the bacterium (Taylor \& Koshland, 1974; Zhulin \& Armitage, 1993).

Another possible function of the glycosylation could reside in the plant root adsorption of $A$. brasilense. Croes 
et al. (1993) demonstrated that the polar flagellum of $A$. brasilense promotes adsorption to plant roots. A plant root lectin could bind the glycan chain(s) on Fla1 or the flagellin itself could act as a lectin recognizing plant sugars.

\section{ACKNOWLEDGEMENTS}

This work was supported by grants of the Fonds voor Geneeskundig Wetenschappelijk Onderzoek (FGWO no. 3.0095.93) and the Flemish Government (GOA Vanderleyden, 1993). S. Moens is a recipient of a fellowship of the Nationaal Fonds voor Wetenschappelijk Onderzoek (NFWO). We thank Dr A. Hartmann and $\mathrm{Dr} M$. Schloter of the Institut für Bodenökologie (Oberschleißheim, Germany) for the monoclonal antibody mAb2. We also thank the Laboratory of Zoological Research of the Limburg University Centre (Diepenbeek, Belgium) for the use of their electron microscopy equipment, and in particular Professor $\mathrm{Dr} \mathrm{J}$. Moens and Professor Dr H. Gevaerts for their expertise in EM.

\section{REFERENCES}

Alam, M. \& Oesterhelt, D. (1984). Morphology, function and isolation of halobacterial flagella. $J$ Mol Biol 176, 459-475.

Ambler, R. P. \& Rees, M. W. (1959). $\varepsilon-N$-Methyl-lysine in bacterial flagellar protein. Nature 184, 56-57.

Bashan, Y. (1986). Migration of the rhizosphere bacteria Azospirillum brasilense and Pseudomonas fluorescens towards wheat roots in the soil. J Gen Microbiol 132, 3407-3414.

Brahamsha, B. \& Greenberg, E.P. (1988). A biochemical and cytological analysis of the complex periplasmic flagella from Spirochaeta aurantia. J Bacteriol 170, 4023-4032.

Brahamsha, B. \& Greenberg, E. P. (1989). Cloning and sequence analysis of $f l a A$, a gene encoding a Spirocbaeta aurantia flagellar filament surface antigen. $J$ Bacteriol 171, 1692-1697.

Croes, C. L., Van Bastelaere, E., De Clercq, E., Eyers, M., Vanderleyden, J. \& Michiels, K. (1991). Identification and mapping of loci involved in motility, adsorption to wheat roots, colony morphology, and growth in minimal medium on the Azospirillum brasilense Sp7 90-MDa plasmid. Plasmid 26, 83-93.

Croes, C. L., Moens, S., Van Bastelaere, E., Vanderleyden, J. \& Michiels, K. W. (1993). The polar flagellum mediates Azospirillum brasilense adsorption to wheat roots. J Gen Microbiol 139, 960-967.

De Mot, R. \& Vanderleyden, J. (1989). Application of twodimensional protein analysis for strain fingerprinting and mutant analysis of Azospirillum species. Can J Microbiol 35, 960-967.

Faguy, D. M., Jarrell, K. F., Kuzio, J. \& Kalmokoff, M. L. (1994). Molecular analysis of archaeal flagellins: similarity to the type IV pilin-transport superfamily widespread in bacteria. Can J Microbiol 40, 67-71.

Hall, P. G. \& Krieg, N. R. (1983). Swarming of Azospirillum brasilense on solid media. Can J Microbiol 29, 1592-1594.

Harlow, E. \& Lane, D. (1988). Antibodies: a Laboratory Manual. Cold Spring Harbor, NY: Cold Spring Harbor Laboratory.

Hartmann, E. \& König, H. (1989). Uridine and dolichyl phosphate activated oligosaccharides are intermediates in the biosynthesis of the S-layer glycoprotein of Methanotbermus fervidus. Arch Microbiol 151, 274-281.

Hartmann, E., Messner, P., Allmeier, G. \& König, H. (1993). Proposed pathway for biosynthesis of the S-layer glycoprotein of Bacillus alvei. J Bacteriol 175, 4515-4519.

Kalmokoff, M. L. \& Jarell, K. F. (1991). Cloning and sequencing of a multigene family encoding the flagellins of Methanococcus voltae. $J$ Bacteriol 173, 7113-7125.

Kalmokoff, M. L., Koval, S. F. \& Jarell, K. F. (1992). Relatedness of the flagellins from methanogens. Arch Microbiol 157, 481-487.

Kelly-Wintenberg, K., South, S. L. \& Montie, T. C. (1993). Tyrosine phosphate in a- and b-type flagellins of Pseudomonas aeruginosa. J Bacteriol 175, 2458-2461.

Laemmli, U. K. (1970). Cleavage of structural proteins during the assembly of the head of bacteriophage T4. Nature 227, 680-685.

Lechner, J. \& Wieland, F. (1989). Structure and biosynthesis of prokaryotic glycoproteins. Annu Rev Biochem 58, 173-194.

Levanony, H. \& Bashan, Y. (1989). Localization of specific antigens of Azospirillum brasilense $\mathrm{Cd}$ in its exopolysaccharide by immunogold staining. Curr Microbiol 18, 145-149.

Logan, S. M., Trust, T. J. \& Guerry, P. (1989). Evidence for posttranslational modification and gene duplication of Campylobacter flagellin. J Bacteriol 171, 3031-3038.

Mescher, M. F. \& Strominger, J. L. (1976). Purification and characterization of a prokaryotic glycoprotein from the cell envelope of Halobacterium salinarium. J Biol Chem 251, 2005-2014.

Messner, P. \& Sleytr, U. B. (1991). Bacterial surface layer glycoproteins. Glycobiology 1, 545-551.

Messner, P. \& Sleytr, U. B. (1992). Crystalline bacterial cell-surface layers. Adv Microb Physiol 33, 213-275.

Michiels, K., Vanderleyden, J., Van Gool, A. P. \& Signer, E. R. (1988). Isolation and characterization of Azospirillum brasilense loci that correct Rbizobium meliloti exoB and exoC mutations. $J$ Bacteriol 170, 5401-5404.

Milcamps, A. (1993). Genome analysis of Azospirillum brasilense for nitrogen fixation: nif, fix and ntr genes. $\mathrm{PhD}$ thesis, Katholieke Universiteit Leuven, Belgium.

Okon, Y. (1994). Azospirillum/Plant Root Associations. Boca Raton, FL: CRC Press.

Penn, C. W. \& Luke, C. L. (1992). Bacterial flagellar diversity and significance in pathogenesis. FEMS Microbiol Lett 100, 331-336.

Petersen, D. J. \& Vanderleyden, J. (1994). Two cloned Azospirillum brasilense genes encode enzymes structurally similar to $\mathrm{AlgC}$ and AlgD of Pseudomonas aeruginosa. In Abstracts of the 93rd General Meeting of the American Study of Microbiology, Las Vegas, Nevada.

van Rhijn, P., Vanstockem, M., Vanderleyden, J. \& De Mot, R. (1990). Isolation of behavioural mutants of Azospirillum brasilense by using Tn5 lacZ. Appl Environ Microbiol 56, 990-996.

Sambrook, J., Fritsch, E. F. \& Maniatis, T. (1989). Molecular Cloning : a Laboratory Manual, 2nd edn. Cold Spring Harbor, NY: Cold Spring Harbor Laboratory.

Sandercock, L. E., MacLeod, A. M., Ong, E. \& Warren, R. A. J. (1994). Non-S-layer glycoproteins in eubacteria. FEMS Microbiol Lett 118, 1-8.

Schloter, M., Moens, S., Croes, C., Reidel, G., Esquenet, M., Hartmann, A. \& Michiels, K. (1994). Characterization of cell surface components of Azospirillum brasilense $\mathrm{Sp} 7$ as antigenic determinants for strain-specific monoclonal antibodies. Microbiology 140, 823-828.

Southam, G., Kalmokoff, M. L., Jarell, K. F., Koval, S. F. \& Beveridge, T. J. (1990). Isolation, characterization and cellular insertion of the flagella from two strains of the archaebacterium Methanospirillum bungatei. J Bacteriol 172, 3221-3228.

Strömqvist, M. \& Grufmann, H. (1992). Periodic acid/Schiff staining of glycoproteins immobilised on a blotting matrix. Bio Techniques 13, 744-746.

Tarrand, J. J., Krieg, N. R. \& Dઠbbereiner, J. (1978). A taxonomic 
study of the Spirillum lipoferum group with description of a new genus, Azospirillum gen. nov. and two species Azospirillum lipoferum (Beijerinck) comb. nov. and Azospirillum brasilense sp. nov. Can J Microbiol 24, 967-980.

Taylor, B. L. \& Koshland, D. E. (1974). Reversal of flagellar rotation in monotrichous and peritrichous bacteria: generation of changes in direction. $J$ Bacteriol 119, 640-642.

Vieille, C. \& Elmerich, C. (1990). Characterization of two Azospirillum brasilense $\mathrm{Sp} 7$ plasmid genes homologous to Rbizobium meliloti nodPQ. Mol Plant-Microbe Interact 3, 389-400.

Wieland, F., Lechner, J. \& Sumper, M. (1982). The cell wall glycoprotein of halobacteria: structural, functional and biosynthetic aspects. Zentralbl Bakteriol Parasitenkd Infektionskr Hyg Abt 1 Orig Reibe C 3, 161-170.

Wieland, F., Paul, G. \& Sumper, M. (1985). Halobacterial flagellins are sulfated glycoproteins. J Biol Chem 260, 15180-15185.
Wilson, D. R. \& Beveridge, T. J. (1993). Bacterial flagellar filaments and their component flagellins. Can J Microbiol 39, 451-472.

Woese, C. R., Kandler, O. \& Wheelis, M. L. (1990). Towards a natural system of organisms: proposal for the domains Archaea, Bacteria, and Eucarya. Proc Natl Acad Sci US A 87, 4576-4579.

Woodward, M. P., Young, W. W., Jr \& Bloodgood, R. A. (1985). Detection of monoclonal antibodies specific for carbohydrate epitopes using periodate oxidation. $J$ Immunol Metbods 78, 143-153.

Yao, R., Macario, A. J. L. \& Conway de Macario, E. (1992). Immunological differences among Methanosarcina mazei S-6 morphologic forms. J Bacteriol 174, 4683-4688.

Zhulin, I. B. \& Armitage, J. P. (1993). Motility, chemokinesis, and methylation-independent chemotaxis in Azospirillum brasilense. $J$ Bacteriol 175, 952-958.

Received 17 February 1995; revised 12 May 1995; accepted 8 June 1995. 